\title{
O RAP SOB A ÓTICA DO INTERACIONISMO SOCIODISCURSIVO
}

The rap under the optics of Sociodiscursive Interactionism

\section{Guilherme da Silva Alves ${ }^{*}$, Marilúcia dos Santos Domingos Striquerr ${ }^{2}$

Artigo Original

${ }^{1}$ Graduado em Letras/Inglês pelo Centro de Letras, Comunicação e Artes da Universidade Estadual do Norte do Paraná, Jacarezinho, Paraná, Brasil.

${ }^{2}$ Doutora em Estudos da Linguagem. Professora da Universidade Estadual do Norte do Paraná, Cornélio Procópio, Paraná, Brasil.

*Correspondência: Centro de Letras, Comunicação e Artes da Universidade Estadual do Norte do Paraná. PR 160, Km O - Cornélio Procópio. Paraná, Brasil. CEP:86.300-000.

\section{Artigo recebido em 18/12/2018 aprovado em 07/10/2019 publicado em 30/12/2019.}

\section{RESUMO}

Este trabalho tem o objetivo de investigar como se configura o gênero textual letra de música, mais especificamente as letras do rap de dois dos mais expressivos rappers brasileiros, Sabotagem e Mano Brown. Para tanto, pautamonos no aporte teórico do Círculo de Bakhtin na definição de gêneros, e de seus estudiosos brasileiros, e nos preceitos metodológicos do Interacionismo Sociodiscursivo. A intenção é conhecer como esse gênero se configura em âmbito social, discurso e linguisticamente. O corpus é formado por cinco exemplares de letra de música rap de Sabotage e Mano Brown. Os resultados demonstraram algumas das características estáveis das letras dos raps compostos por essas duas personalidades.

Palavras-chave: Gêneros textuais. Letra de música. Rap. Interacionismo Sociodiscursivo.

\section{ABSTRACT}

This work has the objective of investigating how to is configured the textual genre: music lyrics, more specifically the rap lyrics of two of the most expressive Brazilian rappers, Sabotage and Mano Brown. Therefore, we are guided by the theoretical contribution of the Bakhtin Circle in the definition of genres, and by its Brazilian scholars, and in the methodological precepts of Sociodiscursive Interactionism. The intention is to know how this gender is configured in social scope, discourse and linguistically. The corpus consists of five copies of rap music lyrics by Sabotage and Mano Brown. The results demonstrated some of the stable characteristics of the letters of raps composed by these two personalities.

Keywords: Textual genre. Music lyrics. Rap. Sociodiscursive Interactionism.

\section{INTRODUÇÃO}

Os gêneros textuais sempre existiram, desde os primórdios dos tempos, e vem se multiplicando com o passar dos anos, principalmente com a evolução da comunicação, uma vez que, segundo Marcuschi (2002), visam atender às necessidades de interação da sociedade e são instrumentos pelos quais as pessoas interagem umas com as outras. Contudo, da mesma forma que vão sendo criados e estabilizados na sociedade, alguns gêneros vão desaparecendo ao longo do tempo, por não atenderem mais os propósitos sociais. Por exemplo, o gênero textual carta pessoal, ainda existe, mas não tão usual quanto antes, na década de 1980, 1990. Antes escrito manualmente e enviada para o destinatário via correios, a carta pessoal com o avanço tecnológico foi 
ganhando novos suportes, novos objetivos e se transformando em outros gêneros, como a carta de reclamação, a carta do leitor, entre outros.

É nesse sentido, que Marcuschi (2002), a partir das definições de Bakhtin (1997), defende que os gêneros textuais são entidades da vida, e que "é impossível se comunicar verbalmente a não ser por algum texto, e em outros termos, partimos da ideia de que a comunicação verbal só é possível por algum gênero textual" (MARCUSCHI, 2002, p. 22). Logo, entre os inúmeros gêneros existentes, interessamonos em conhecer o gênero textual letra de música, de forma mais específica, a letra do estilo músical: rap, e ainda, do rap composto por dois dos mais conhecidos rappers brasileiros: Sabotage e Mano Brown.

De acordo com os estudos de Janotti Jr. (2003), o rap se destaca por ter como destinatário/público alvo à camada popular da sociedade, uma vez que se propõe a tratar e fazer refletir sobre questões que envolvem as políticas públicas, ou a falta delas, para a periferia dos centros urbanos. O rap seria então uma forma de representação da realidade da grande massa que vive na periferia marginalizada. Assim, como moradores da periferia de um município do interior paulista, interessamo-nos em compreender um pouco mais sobre o referido gênero. Para tanto, tomamos como aporte teórico a definição de gêneros estabelecida pelo Círculo de Bakhtin e a proposta de análise de gêneros textuais elaborada por Barros (2012), por meio de um dispositivo denominado pela autora de Dispositivo didático de gêneros.

Portanto, esse trabalho tem o objetivo de apresentar algumas das características estáveis da letra de música rap, de composição dos rappers Sabotagem e Mano Brown.

\section{MATERIAIS E MÉTODOS}

De acordo com os preceitos de Bakhtin (1997), toda comunicação se estabelece dentro de situações comunicativas, ou esferas sociais de linguagem, e porque são inúmeras as situações comunicativas existentes na sociedade, são diversos e diferentes gêneros do discurso utilizados pelas pessoas cotidianamente para interagirem umas com as outras. Nesse sentido, as pessoas interagem, sempre, por meio de gêneros, que são formas de discursos que se originam, se estabelecem e se estabilizam dentro das esferas sociais. Por exemplo, para participar da esfera publicitária, com o objetivo de influenciar pessoas a comprar um produto ou serviço, o publicitário elabora um anúncio, que é um gênero específico.

Dada a imensa variedade de gêneros, Rojo e Barbosa (2015), expõem, a partir dos preceitos de Bakhtin (1997), que os gêneros podem ser divididos em dois grandes grupos, os gêneros primários e os secundários. Gêneros primários são os que participam de atividades mais simples, do cotidiano das pessoas, como os cumprimentos, as conversas informais e, numa abordagem atual, o tweet e certas postagens em redes sociais. Todos esses gêneros, por serem interações espontâneas e cotidianas, onde a estrutura do diálogo é mais simples, podem ser considerados gêneros primários. Já os gêneros secundários são mais complexos, têm finalidade pública e um caráter mais formal, como no caso das notícias e das redações escolares. No caso da letra de música, incluindo todos os estilos musicais além do rap, o entendimento é de que é um gênero secundário, por envolverem questões sociocomunicativas complexas.

Uma outra classificação realizada sobre os gêneros que auxilia na compreensão do que é esse fenômeno, é a diferença entre tipos de texto e de gêneros textuais. Marcuschi (2002) explica que tipos de textos são categorias de uma gramática de texto, aspectos linguísticos que segmentam e organizam os 
textos, os quais podem ser identificados em: narração, argumentação, exposição, descrição, injunção. Por outro lado, gêneros textuais são entidades da vida, e por isso "se os tipos textuais são apenas meia dúzia, os gêneros são inúmeros" (MARCUSCHI 2002, p. 29). Exemplos de gêneros: letra de música, artigo científico, notícia jornalística, romance, entre outros. Cada gênero comporta um ou mais tipos de texto. Por exemplo, o romance é formado por sequências da narração, da descrição.

Explica Bakhtim (1997) que todos esses aspectos são refletidos nos três elementos que formam todo e qualquer gênero: o conteúdo temático, o estilo e a construção composicional. Segundo o autor, o conteúdo temático é o elemento mais importante do enunciado, pois refere-se ao assunto tratado no texto, mais a valoração que o autor empenha ao tema. Quanto ao estilo, trata-se dos aspectos gramaticais que formam o gênero. Todo enunciado é individual, podendo refletir a individualidade do falante, mas nem todos os gêneros possibilitam essa individualidade, considerando que, o estilo linguístico não é do autor, mas do gênero. Alguns gêneros mais formais exigem uma forma mais padronizada, como documentos oficiais e a notícia de jornal, proibindo o uso de advérbios e adjetivos, por exemplo.

E no caso da construção composicional é, segundo Rojo e Barbosa (2015, p. 27), “a organização e o acabamento do todo do enunciado, do texto como um todo". É a estrutura do texto propriamente dita, os recursos utilizados para estruturar o gênero, como a fórmula "e foram felizes para sempre" encontradas nas fábulas e em alguns contos.

Norteados por esses princípios, os pesquisadores da corrente teórico-metodológica do Interacionismo Sociodiscursivo (ISD) sugerem que para que seja possível conhecer detalhadamente um determinado gênero é possível aplicar a um conjunto de exemplares do gênero em questão, um procedimento de análise, que leva em conta a esfera social da qual participa o gênero, a prática social de linguagem que ele materializa, os elementos que formam o contexto de produção e a infraestrutura textual. Procedimento que foi resumido e didatizado por Barros (2012) em uma ferramenta intitulada de Dispositivo didático do gênero, o qual é formado por perguntas direcionadoras da ação de pesquisa do analista.

O Dispositivo é o que utilizamos para análise de nosso corpus, em busca de compreender algumas das principais características que formam a letra da música rap.

\section{RESULTADOS E DISCUSSÃO}

De acordo com Barros (2012), antes da aplicação do Dispositivo didático de gênero é preciso que $\mathrm{o}$ analista realize uma pesquisa bibliográfica, a fim de conhecer os conceitos teóricos a respeito do gênero em estudo. A seguir, apresentamos as definições de letra de música, gênero que consideramos mais geral, mais abrangente, e da letra da música rap, segundo especialistas no assunto.

Para Frith (1998), a música tem um impacto importante na identificação da cultura de uma nação. No Brasil, é comum nos depararmos com os estilos como o samba, o rock, o rap, o funk, o sertanejo. A popularidade e a frequência com que esses estilos musicais aparecem variam com base no tema, região geográfica e questões sociais que envolvem o público alvo ao qual se destina o texto. Por exemplo, as modas de viola nasceram no campo, nas áreas rurais do interior do país, com o tempo, foram ganhando espaço e se difundindo nos grandes centros. É o que ocorreu também com o rap, que nasceu e se estabeleceu nas periferias das grandes 
cidades, mas que foi ganhando espaço outros lugares.

Defende Frith (1998), que em alguns casos, o próprio nome dado ao gênero musical reflete a imagem de seus participantes, de seu compositor/cantor e de seus ouvintes, como é o caso da música caipira, antes destinada a um público assim denominado caipira por morar ou estar próximo à área rural, a cultura da agropecuária, da roça. A realidade da sociedade em que inserido o texto também é que o aproxima de um estilo ou de outro. Para Frith $(1998,77)$, a letra de música "é uma conversa silenciosa que acontece entre o consumidor, que sabe asperamente o que quer e o vendedor, que trabalha copiosamente, para imaginar o padrão dinâmico dessas demandas".

No mesmo sentido, explicam Cunha, Costa e Cezário (2003) que exatamente por uma letra estar direcionada a um público específico, a variação linguística aplicada na construção desse gênero, no estilo (BAKHTIN, 1997), é a utilizada por seus leitores/ouvintes. Por esse motivo, a norma culta da língua, as regras sintáticas e gramaticais não são propositalmente objeto de atenção. Por exemplo, desatenção proposital à concordância, quebras de palavras e sílabas, a coesão textual muitas vezes acaba ficando em segundo plano, focando principalmente no entendimento da mensagem e no funcionamento do ritmo e da melodia. As ocorrências desses fatos refletem a relação do texto com o mundo dos participantes, como forma de ação e reação: o autor/compositor se apresenta como parte de um grupo específico e com interesses específicos, e o receptor promove a reflexão e a interação com a realidade vivida ao longo de sua vida, onde a linguagem familiar reflete a aproximação entre os dois pontos do discurso, como parte de um mesmo grupo social.

O autor/compositor de letra de música recorre ainda a alguns outros recursos estilísticos, segundo Costa (2008), como as metáforas, onomatopeias, as quais deixam de serem apenas imitações de sons, formando ritmos e em alguns casos, parte do conteúdo.

Outro ponto importante é a estrutura não linear presente nesse gênero, que em conjunto com a linguagem subjetiva, abre espaço para a livre interpretação do leitor/ouvinte, com base em suas experiências pessoais. Assim, a letra de música segue sua própria estrutura, embora se assemelhe a outras, por exemplo, a estrutura parecida com a do poema: com versos, rimas, estrofes, figuras de linguagem e alguns temas em comum, se dispersa na existência de algumas especificidades como o refrão, a melodia e as anáforas, assim como os temas por vezes refletidos em crônicas e outros gêneros narrativos esbarram na própria estrutura em versos (MELLO, online).

\section{A letra da música rap}

Entre os mais variados gêneros musicais existentes na sociedade, destacamos o rap, que é um estilo originário das periferias da Jamaica, de acordo com Janotti Jr. (2003), e, levado aos Estados Unidos e difundido para o resto do mundo na década de 1970.

O Rap caracteriza-se pela construção de poesia improvisada, em tempo rápido, acompanhado, por vezes, de uma batida forte rítmica que se faz sem o auxílio de qualquer instrumento musical. Nesse sentido, conforme Janotti Jr. (2003), o rap é um modo de expressão 
conectado à poesia oral, reproduzido em conjunto a uma base rítmica.

Explica ainda Janotti Jr. (2003), que o rap se engloba no hip-hop, movimento que surgiu nos anos de 1970, nas periferias de Nova York, principalmente através das danças de rua e do grafite, como formas de protesto contra o preconceito as minorias, e como retrato da periferia pobre e negra. Essas críticas foram transformadas em versos poéticos, acompanhadas de ritmos que traduziam os ideais do movimento da periferia.

No Brasil, o rap apareceu no cenário musical no fim da década 1980, em São Paulo, e sofreu forte preconceito, de acordo com Souza (2011), por retratar a violência em suas letras e por ser tipicamente oriundo da periferia, das chamadas favelas. Somente no final da década de 1990, o estilo ganhou a atenção da mídia, primeiramente com o rapper Thaíde e com o DJ Hum, o que influenciou novos grupos como os Racionais MC's, do qual participava Mano Brow e novos rappers como Sabotage.

Para Souza (2011), conhecido como "trilha sonora da favela", o rap é capaz de produzir uma leitura crítica da sociedade, se alimentando das gírias e expressões locais e recorrendo ao passado da população negra, utilizando em toda sua composição elementos típicos da periferia, estabelecendo um círculo funcional onde três vertentes se identificam: o rapper, representante legítimo da periferia, em sua ótica e linguagem; o povo da periferia, com visão de mundo e estilo de linguagem semelhante à do autor; e o tema comum entre os dois participantes do discurso.

Se tratando de um movimento cultural, explica Bentes (2008) que o rap extrapolou os limites da música, construindo um traço de identidade comum para seus envolvidos, que pode ser observado nos costumes, nas vestes, na linguagem e nos comportamentos sociais. No caso do rapper Sabotage, um dos precursores e mais influentes da cultura rapper brasileira, ele repete em quase todas suas letras e no título de um de seus álbuns, o que seria o legado do movimento no país, o laço entre o rap e a sociedade, que deve ser respeitado por todos: "O rap é compromisso". Nesse sentido, como exemplares do gênero que formam nosso corpus, selecionamos cinco letras de rap de dois dos maiores compositores deste estilo musical no Brasil, "No Brooklin" e "Canão foi tão bom", do rapper Sabotage; e "Jesus chorou", "Fim de semana no parque" e "A vida é desafio", do grupo rapper Racionais $\mathrm{MC}^{\prime} \mathrm{s}^{1}$.

Seguindo as questões que formam o Dispositivo didático de Barros (2012), a prática social que o gênero está vinculado é a de divulgar e fazer as pessoas refletirem sobre a realidade das periferias dos centros urbanos: a situação de preconceito, abandono político/público, os hábitos e costumes que vão se estabelecendo a fim de que a população possa sobreviver. É um gênero que se estrutura na modalidade oral e escrita da língua, contudo, os exemplares analisados são produções escritas.

A esfera social de linguagem a que pertence o gênero é a artística, a qual tem como características gerais o entretenimento, o livre modo de expressão de seus autores/compositores, que visam relatar experiências de uma comunidade, por isso, conforme explica Viana (2007) o rap é a expressão figurativa da realidade.

Quem produz esse gênero são compositores chamados nesse segmento musical de rappers, 
geralmente, moradores ou simpatizantes das comunidades de periferias dos centros urbanos. E, o papel discursivo que assume o produtor é buscar fazer o público refletir sobre uma ideologia, sobre os acontecimentos, sobre o meio de vida, os preconceitos e dificuldades que vivem os moradores das comunidades mais carentes social e economicamente. No caso de nossos cinco exemplares em análise, a letra "No Brooklin" é de autoria de Mauro Mateus dos Santos, conhecido como Sabotage, e gravada por ele em parceria com a cantora Negra Li; e "Canão foi tão bom" é do Sabotage com participação de DBS A Quadrilha, Lakers e Negra Li.

Sabotage ou "maestro do Canão", como era conhecido pela influência do local onde morava, Favela do Canão, localizada no bairro do Brooklin, na zona Sul de São Paulo, foi assaltante e gerente de tráfico. O apelido Sabotage é de infância. Como muitos dos adolescentes negros e moradores das favelas de São Paulo, teve diversos familiares mortos pelo crime; foi interno na antiga FEBEN (atual Fundação Casa), indiciado por porte ilegal de armas e tráfico de drogas. Narrando acontecimentos da realidade em que vivia e criticando o sistema, representou em suas músicas os negros da periferia. Morreu assassinado em um acerto de contas entre gangues rivais pelo tráfico de drogas, em janeiro de 2003.

A letra "Jesus Chorou" é de composição de Pedro Paulo Soares Pereira, conhecido como Mano Brown, integrante e principal vocalista do grupo Racionais MC's; "Fim de semana no parque" é de Mano Brown e Edi Rock, com a participação de Edi Rock e Ice Blue, pilares do grupo Racionais MC's, também de Netinho de Paula; "A vida é desafio" é de Edi Rock, rapper integrante do grupo Racionais MC's. Mano Brown, nasceu em São Paulo em 1970, recebeu esse apelido porque no início de sua carreira suas músicas se relacionam com as James Brown, e pela ambiguidade nas músicas em que o cantor dizia: "Sou eu, o Mano Brown" (Fim de semana no parque, Raio X do Brasil, Racionais MC's, 1993). Cresceu na periferia, no bairro do Capão Redondo (Parque Santo Antonio), extremo sul de São Paulo. Representa sua comunidade, na exposição da desigualdade em que viveu e que faz parte de seu cotidiano, envolvendo conflitos, drogas e preconceitos. O compositor ganhou destaque por seu conflito constante relacionado à mídia em geral. Até hoje, são encontradas pouquíssimas entrevistas para revistas, jornais e programas de rádio e TV. Na Televisão, além de raras aparições em programas de tom mais casual, como "Altas Horas" da Rede Globo e "Pânico na TV" da Rede TV, Brown aparece apenas em transmissões de shows ao vivo².

Os destinatários/público alvo dos raps são os membros das comunidades das periferias e/ou aqueles se interessam pela cultura desse local e/ou pelo ritmo musical e/ou pela cultura do rap de uma forma geral.

A finalidade de quem produz o rap é, então, representar a periferia, dirigir e divulgar críticas ao poder público, à superioridade branca e elitizada da sociedade; à mídia; aos diversos tipos de preconceito contra um grupo social-econômico-cultural. Em decorrência, os temas tratados nesse gênero são as situações vividas na periferia: No caso de nossos exemplares, na letra de música "No Brooklin", o rapper Sabotage narra um trecho de sua história 
dentro do bairro onde morava envolvendo drogas, conflitos e desprezo. O foco principal é o crescimento pessoal do rapper, aliado ao modo de viver imposto pela periferia, como aparece no refrão: "Zona sul, no Brooklin aprendi viver, e o respeito de um por um, faz a paz prevalecer" (No Brooklin, Rap é compromisso, Sabotage, 2000). Semelhante ao exemplo anterior, em "Canão foi tão bom", Sabotage narra mais um trecho de sua história e deixa vários conselhos para que seus fãs e amigos consigam fugir da realidade de que fazem parte. Em um tom de revolta e medo, o refrão deixa explícito o tema central da música: "Brooklin, o que será de ti? Regar a paz eu vim, Jesus já foi assim, brigas traz intrigas, ai de mim..." (Canão foi tão bom, Sabotage, 2016).

Na letra de música "Jesus Chorou", Mano Brown narra uma de suas histórias na periferia onde morava. O título indica que com todas as dificuldades vividas dentro da periferia é permitido demonstrar fraquezas: "A lágrima de um homem vai cair, esse é o seu B.O pra eternidade, diz que homem não chora, tá bom, falou, não vai pra grupo irmão, aí, Jesus chorou". Já em "Fim de semana no parque", Mano Brown e Edi Rock criticam à desigualdade e superioridade do povo branco e moradores dos bairros nobres:

Daqui eu vejo uma caranga do ano, toda equipada e o tiozinho guiando, com seus filhos ao lado estão indo ao parque, eufóricos brinquedos eletrônicos, automaticamente eu imagino, a molecada lá da área como é que tá, provavelmente correndo pra lá e pra cá, jogando bola descalço nas ruas de terra, é, brincam do jeito que dá. (Fim de semana no parque, Raio X do Brasil, Racionais MC's, 1993).

Em "A vida é desafio", há um incentivo aos moradores da periferia a mudarem suas vidas, buscarem a felicidade, dinheiro e o sucesso; há uma crítica ao sistema e aos preconceitos: “'É necessário sempre acreditar que o sonho é possível, que o céu é o limite e você, truta, é imbatível, que o tempo ruim vai passar, é só uma fase, e o sofrimento alimenta mais a sua coragem". (A vida é desafio, Nada como um dia após um outro dia, Racionais MC's, 2002).

Decorrente da finalidade, o valor desse gênero na sociedade é de grande impacto social, principalmente, por pessoas que se identificam de alguma forma com o que é narrado nas letras. Assim, o autor/compositor se identifica como parte do mesmo grupo social de seus destinatários, compartilhando a mesma linguagem, dificuldades e na maioria das vezes a ideologia.

A letra de música tem como suportes os discos de Vinil, Cds, Dvds, e ambientes virtuais de um modo geral. No caso de nossos exemplares: A música "No brooklin" faz parte do álbum "Rap é compromisso", gravado em disco de vinil e CD, no ano de 2000; "Canão foi tão bom" faz parte do álbum póstumo intitulado "Sabotage", gravado em $C D$, no ano de 2016; "Jesus chorou" e "A vida é desafio" fazem parte do álbum "Nada como um dia após o outro dia", gravado em Disco de Vinil e CD no ano de 2002; "Fim de Semana no parque" faz parte do álbum "Raio X do Brasil", gravado em Disco de Vinil, no ano de 1993. Além destes suportes, todos os nossos exemplares estão disponíveis em variados aplicativos de internet.

Quanto aos elementos que formam as características discursivas do gênero, o tipo de discurso predominante é o expor interativo, por exemplo: "Amo minha raça, luto pela cor, o que quer que eu faça é por nós, por amor" (Jesus Chorou, Nada como um dia após o outro dia, Racionais MC's, 2002). Nesse trecho, Mano Brown fala na primeira pessoa do singular, "amo", indicando que viveu os 
fatos tratados na letra da música, ou simula ter vivido, deixando explícito a sua relação com a comunidade retratada na letra.

O local onde acontece a narrativa e para quem Mano Brown direciona sua fala está explícito em todo o texto, a relação entre o autor/compositor e os destinatários junto a periferia está explícita principalmente na escolha da linguagem informal, cheia de gírias da periferia, exemplos: "Quem me tirou vou embaçar, eu não devo, eu não cagueto pra pipoca querer me tira" (No Brooklin, Rap é compromisso, Sabotage, 2000); "Várias famílias, vários barracos, uma mina grávida, e o mano tá lá, trancafiado" (A vida é desafio, Nada como um dia após um outro dia, Racionais MC's, 2002). Aqui, destacamos a palavra "mano", presente em todos os exemplares e no cotidiano de muitos grupos de homens e mulheres que levam o conceito de “irmão", originado na periferia, pela representação da igualdade buscada pelos representantes dessa camada social, como membros da mesma família, compartilhando a realidade, conflitos e sentimentos.

Sobre o tipo de sequência tipológica, a sequência do relatar é a predominante. É um relatar de acontecimentos vividos. Os autores narram realidades da sociedade em que vivem, por vezes algo que possa acontecer, mas que já faz parte do cotidiano naquela realidade: "No Brooklin lembrei sim, foram várias leis, e o veneno, sofrimento passado ali dentro, por ali tudo mudou, mas eu não posso moscar, o que é aquilo? Lá vem tiro, é os pilantra se pá" (No Brooklin, Rap é compromisso, Sabotage, 2000).

Quanto ao plano geral que caracteriza a letra de música rap, há uma apresentação de título e do texto propriamente dito, e nome do(s) compositor(es). Os textos são divididos em estrofes livres, com números variados de versos; possuem refrão; extensão também é livre. Sobre os elementos linguísticos que caracterizam a organização do conteúdo temático, destacamos as retomadas com o emprego de pronomes, exemplos: "Feliz e agitada, toda a playboyzada, as garagens abertas eles lavam os carros" (Fim de semana no parque, Raio X do Brasil, Racionais MC's, 1993), “Eu penso mil fitas, vou enlouquecer" (Jesus Chorou, Nada como um dia após o outro dia, Racionais $\mathrm{MC}^{\prime} \mathrm{s}$, 2002), "Lembrar das minas, mulher vocês são lindas" (Canão foi tão bom, álbum Sabotage, Sabotage, 2016). A estratégia da repetição também é utilizada, por meio da repetição do pronome eu, por exemplo, servindo como uma forma de representação e aproximação do autor ao cotidiano dos receptores, como alguém que realmente viveu aquelas situações: "esse conselho eu vim pra seguir", "Mas eu não posso moscar", "Esse conselho eu venho buscando" (No Brooklin, Rap é compromisso, Sabotage, 2000), "E eu que me julguei forte", "E eu que me senti", "Deixa eu caminhar contra o vento" (Jesus Chorou, Nada como um dia após o outro dia, Racionais MC's, 2002).

O paralelismo se identifica pela repetição da construção da frase, de estruturas sintáticas ou semânticas, uma sequência de expressões, que seguem uma estrutura paralela. No caso de nossos exemplares, há uma forma de paralelismo conhecido como anafórico, encontrada geralmente na literatura, que assim como as anáforas, característica que também faz parte da composição do gênero, tende a seguir uma simetria sintática e semântica em suas repetições, em grande parte no início dos versos. Como parte da esfera artística, da 
semelhança com o poema, e principalmente pela presença da anáfora, é possível identificar o emprego desta estratégia linguística em vários momentos da composição desses textos: "Falo do enfermo, irmão, falo do são então, falo da rua" "Ele sonha na direta com a liberdade, Ele sonha em um dia voltar...", além da narração direta, com a narração de fatos que aconteceram em sequência, explicando ou retomando algo que foi dito na oração anterior: "Se abriu que nem uma flor, ficou louco. Tava eu, mais dois trutas e uma mina" (Jesus Chorou, Nada como um dia após o outro dia, Racionais MC's, 2002).

Os conectivos mais usados são os espaciais, para representar o local e o tempo em que determinada situação aconteceu ou acontecerá, os autores retomam aos cenários comuns aos moradores da periferia em boa parte dos textos, para reforçar a ideia de que o autor também faz parte daquela realidade: "Vamos passear no parque", "Na periferia a alegria é igual" (Fim de semana no parque, Raio X do Brasil, Racionais MC's, 1993).

Os substantivos que mais aparecem são os abstratos, os produtores rappers priorizam em suas letras o sentimento, principalmente a raiva e a revolta, à tristeza e a mágoa, sobre as dificuldades encontradas no cotidiano e pelas perdas e desilusões, além da busca por seus direitos: "Sem ter medo de colar, cheguei no sapatinho", "Favela pede paz, lazer, cultura, inteligência não muvuca" (No Brooklin, Rap é compromisso, Sabotage, 2000).

Os verbos de ação são mais presentes, ainda levando em consideração o fato de que o rapper buscar narrar os acontecimentos e conflitos da periferia: "Quem me tirou, vou embaçar, eu não devo, eu não cagueto..." (No Brooklin, Rap é compromisso, Sabotage, 2000), "Se eu catar, a boa numa hora dessa, vou me destacar pro outro depressa, vou comprar uma house de boy, depois alugo..." (Jesus Chorou, Nada como um dia após o outro dia, Racionais MC's, 2002).

O rap tem como característica o ritmo intenso e ininterrupto, nesses casos, acompanhados de batidas fortes. Assim, poucas vírgulas aparecem, mais para o funcionamento do ritmo do que do próprio texto: “Quero, sim, se essa é a pergunta, mas a dona Ana fez de mim um homem e não uma puta" (Jesus Chorou, Nada como um dia após o outro dia, Racionais MC's, 2002), diferentemente do ponto de interrogação e exclamação, que aparece quase na mesma frequência das vírgulas, mas com o objetivo de questionar e afrontar o receptor ou representar uma fala agressiva em um diálogo dentro do texto: "Faz seu mundo, não, jão!", "Cadê meu sorriso? Onde tá? Quem roubou?" (Jesus Chorou, Nada como um dia após o outro dia, Racionais MC's, 2002).

Há uso de metáforas em várias oportunidades, na maioria das vezes em forma de gírias. Os autores do rap utilizam as metáforas em sua composição para exprimir um sentimento extremo da situação, exagerado, com um tom de revolta, ao mesmo tempo em que estreita a relação com o receptor, que por sua vez, para que haja o sentido, necessita do conhecimento prévio da expressão: "O que é o que é? Clara e salgada; Cabe em um olho e pesa uma tonelada", "Pra semente eu não vim" (Jesus Chorou, Nada como um dia após o outro dia, Racionais MC's, 2002).

As vozes do texto são predominantemente dos autores. Raros diálogos também aparecem, entre o próprio autor e outros personagens, 
geralmente amigos e integrantes da banda, que estavam ou vivenciaram um dos acontecimentos narrados nos textos. Vozes do senso comum, os autores geralmente compartilham a mesma ideologia de seus receptores, na busca pela reinvenção da periferia e na busca pelos seus direitos, como membro da mesma sociedade.

\section{CONCLUSÃO}

Os resultados de nossas análises a cinco exemplares de letras de rap demonstraram que os raps produzidos por Sabotage e Mano Brow estão inseridos na esfera artística e têm como prática social de linguagem a proposta de reflexão sobre a realidade das periferias dos centros urbanos, com forte influência sobre os moradores dos subúrbios do país, sobretudo nas periferias dos grandes centros, por meio do laço afetivo entre autor/compositor e seus destinatários que compartilham a mesma realidade, conflitos, espaço e ideais. Seguindo o dispositivo elaborado por Barros (2012), foi possível identificar algumas outras importantes características que evidenciam os objetivos e o papel que o gênero ocupa na sociedade, a intencionalidade discursiva, o uso da linguagem informal na afirmação do local onde acontecem os conflitos em vários momentos do texto e os temas, que demonstram a identidade do autor e o compromisso com a sociedade da qual faz parte, que tem no rap, um modo de expressão, onde pode representar e propiciar a busca pelos direitos, com o objetivo de alcançar a igualdade, ou a superioridade.

Todos os autores declararam não haver qualquer potencial conflito de interesses referente a este artigo.

\section{REFERÊNCIAS}

BAKHTIN, Mickail. Estética da criação verbal. Tradução Maria Ermantina Galvão G. Pereira. 4. ed. São Paulo/SP: Martins Fontes, 2003.

BARROS, E. M. D. Transposição didática externa: a modelização do gênero na pesquisa colaborativa. Raído, v. 6, n. 11, p 11-35, 2012.

BENTES, A.C.; FERNANDES, F. A poesia oral nas bordas do mundo: identidades em movimentos nos videoclipes brasileiros de rap. In: LEITE, Eudes Fernandes, FERNANDES, Frederico. (orgs.) Oralidade e literatura: outras veredas da voz. Londrina: EDUEL,2007.

FRITH, Simon. Performing Rites: on the value of popular music. Cambridge/Massachusett: Havard University Press, 1998

FURTADO DA CUNHA, Maria Angélica, COSTA, Marcos Antonio e CEZARIO, Maria Maura. Linguística funcional teoria e prática. Rio de Janeiro, DP\&A editora - FAPERJ, 2003, p.29.

JANOTTI JR., Jeder. Aumenta que isso aí é rock and roll: mídia, gênero musical e identidade. Rio de Janeiro: E-papers, 2003.

MARCUSCHI, Luiz Antônio. Gêneros textuais: definição e funcionalidade. In: DIONISIO, Angela Paiva; MACHADO, Anna Rachel; BEZERRA, Maria Auxiliadora (Org). Gêneros Textuais e Ensino. Rio de janeiro: Lucerna, 2002.

ROJO, Roxane; BARBOSA, Jaqueline $P$. Hipermodernidade, multiletramentos e gêneros discursivos. São Paulo. Parábola, 2015.

SOUZA, A.L. S. Letramentos de reexistência: poesia, grafite, música, dança: HIPHOP. São Paulo: Parábola Editorial, 2011.

VIANA, Nildo. A Esfera Artística. Marx, Weber, Bourdieu e a Sociologia da Arte. Porto Alegre: Zouk, 2007. 